\title{
That human touch
}

\author{
In this issue, Nature Energy takes a closer look at some of the ways in which the social sciences are \\ addressing problems in energy and climate change.
}

The challenges of energy and climate change faced today by society call for greater scientific and technological understanding, but also greater understanding of the role of people and social systems. Only through such a multifaceted approach can we hope to find real and lasting solutions. The presentation of leading research from the social sciences alongside that from the natural sciences is thus a core aim of Nature Energy and our sister publication, Nature Climate Change.

The case for the value of the social sciences has been argued many times before. But what do we mean when we talk about 'the social sciences', and what kind of contributions can they make to the challenges of energy and climate change? This month, Nature Energy and Nature Climate Change explore the different dimensions of these questions through a collection of articles spanning representative subdisciplines and fields.

In considering the first of these questions, thinking of the social sciences as a homogeneous, single entity is no more illuminating or instructive than thinking of the natural sciences in the same way. The social sciences are as varied and diverse as the natural sciences, with their own languages, approaches and formalities.

Nor does it do to assume that they alone have the answer, any more than it does to say that the natural sciences do. This is why there is so much value in coming together: sharing insights from each field - across all fields - can only make us stronger as a whole. There are gains to be made through multidisciplinary projects, but also simply by having an increased awareness of one another and the discoveries each are making.

To that end, moving towards a greater understanding of the diversity of topics within the social sciences is an important step. In this issue of Nature Energy, we present four pieces that shed light broadly on economics, psychology and sociology, as well as on organizational studies, transition studies, innovation studies, ethics, justice and environmental studies. Meanwhile, Nature Climate Change will additionally discuss decision science, policy analysis and political science. These areas, while not an exhaustive list, all play key roles for understanding and making decisions about our energy systems. They both inform and are informed by science and technology.

Paul Stern and colleagues (article number 16043) review work from social, behavioural and economic sciences looking for routes to reduce fossil fuel consumption by the residential and business sectors. Much can be achieved through development of more efficient or clean energy technologies, yet significant opportunities exist that address behavioural patterns and the way in which energy is used by ordinary consumers, by industrial and commercial enterprises, and by governmental and non-governmental bodies. Insights here can produce interventions that reshape our energy consumption, helping to meet our climate goals. As Stern et al. discuss, knowledge gained in this area has ramifications on many timescales, from the immediate to the generational. When considering the average replacement time for boilers, cars and other home electronic devices, the importance of this cannot be overstated.

The moral aspects of our energy use are also significant - not just in terms of climate change, but also for other pressing concerns, including impact on the environment or on individuals and communities. In their Perspective, Benjamin Sovacool and colleagues (article number 16024) examine concepts from justice and ethics, and apply them to a range of energy problems: involuntary resettlement caused by infrastructure projects, pollution, energy poverty, nuclear waste and climate change. Their analysis enables them to propose an energy justice framework that offers elements for decisionmaking that are frequently overlooked by techno-economic approaches, but that can have important and long-term ramifications.

As is frequently stated, the transition of our energy system - to whatever it may look like in the future - will be shaped by ordinary people. We each have a role to play as energy users, whether consciously or unconsciously. These roles will be different for us all, depending on our habits and routines; treating us as simple, rational actors with the same responses fails to capture the unique and important ways in which different groups of people might facilitate and enable change or halt the process. To that end, Johan Schot and colleagues (article number 16054) provide an overview of the work on user participation in energy systems, and highlight categories that typify the different user roles in an energy transition process. The five roles they identify demonstrate the various ways in which we each operate and respond to new energy technologies, and can offer constructive ways to think about adoption and practice change if we are going to move to a decarbonized, energy-efficient world.

Finally, the notion of participation is increasingly critical to thinking about large-scale renewable energy infrastructure projects. Transmission-scale solar or wind farms are becoming more and more common, but to increase their penetration of the energy market, it is essential to increase their public support as well as their technological capability. Yet, renewable infrastructure often meets resistance on the local scale. Through increased public participation in such projects, it is hoped that public attitudes towards them can be altered. Social sciences can help to identify and understand the diversity of opinion, deepening our understanding of community concerns. As a result, social sciences can help to improve the process of public participation and shared ownership. David Bidwell explores this in his Comment (article number 16051) and proposes a framework for discussing participation in renewable energy decisions. The questions he poses highlight important areas for further consideration and research when approaching future renewables projects.

The ideas and themes presented in this collection are not comprehensive; there are many other efforts in the social sciences, some of which will be discussed in Nature Climate Change. Nonetheless, what we hope becomes apparent from the pieces presented this month is the breadth and variety of topics that have an important contribution to the overall challenge of energy and climate change. Much work remains to be done; we look forward to bringing you more of it in the future. 